\title{
Offer and Use of Smoking-Cessation Support by Depression/Anxiety Status: A Cross-Sectional Survey
}

\author{
Jennifer A. L. McGowan, ${ }^{1}$ Jamie Brown, ${ }^{1}$ Robert West, ${ }^{1}$ Leonie S. Brose, ${ }^{2}$ and Lion Shahab ${ }^{1}$ \\ ${ }^{1}$ Department of Behavioural Science and Health, University College London, London, UK \\ ${ }^{2}$ Addictions Department, Institute of Psychiatry, Psychology and Neuroscience (IoPPN), King's College London, London, UK
}

\begin{abstract}
ntroduction: Higher levels of anxiety and depression have been found to be associated with greater difficulty in stopping smoking. This raises the question as to whether mood disturbance may be associated with exposure to, and use of, quitting support.

Aims: This study examined whether General Practitioner (GP) advice and/or offer of support, or stopsmoking service use differed between smokers reporting or not reporting depression/anxiety.

Methods: Data came from the Smoking Toolkit Study. Participants were 1,162 English adults who reported currently smoking or having stopped within the past 12 months, aged 40+ years, surveyed between April and September 2012. Anxiety/depression was assessed by the mood disturbance item of the EuroQol five dimensions questionnaire (EQ-5D). This was compared to recall of GP quit advice and/or support, and stop-smoking aid use adjusting for age, gender, and social grade.

Results/Findings: Smokers reporting depression/anxiety were more likely to recall being offered advice and support to stop smoking by their $\mathrm{GP}(\mathrm{OR}=1.50,95 \%$ C.I. $=1.05-2.13)$. However, there were no significant differences in use of stop-smoking aids during the past year.

Conclusions: Smokers reporting depression/anxiety are more likely to be offered stop-smoking support by their GPs, but this does not appear to translate into stop-smoking aid use, despite high motivation to quit. Given higher nicotine dependence in this group, mental health specific support may need to be offered, and more needs to be done to make this offer of aid attractive.
\end{abstract}

\section{Introduction}

Individuals diagnosed with mental health problems have a reduced life expectancy compared with people without, and this difference is commonly attributed to lifestyle factors, such as smoking (De Hert et al., 2011; Hert et al., 2011; Musuuza et al., 2013; Osborn et al., 2007). For example, a cohort study of adults with and without serious psychological distress reported that current smokers with psychological distress lost an average of 14.9 life years, compared to never-smokers without psychological distress (Tam, Warner, \& Meza, 2016). Furthermore, in heavy smokers alone, the presence of mental illness reduces life expectancy by 8-10 years (Chesney, Goodwin, \& Fazel, 2014). In depression, for instance, tobaccorelated conditions account for roughly $50 \%$ of excess mortality (Callaghan et al., 2014). There are also associated economic costs; in 2009/10, the indirect and direct cost to the economy for smokers reporting mental health

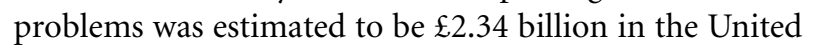
Kingdom (Wu, Szatkowski, Britton, \& Parrott, 2013). The most common mental disorders in the United Kingdom are anxiety (5.9\%) and depression (3.3\%) (15.7\% combined prevalence; Office of National Statistics, 2007) and, within these, smoking rates are reported at $39.8 \%$ for adults with depression and $37.4 \%$ for those with anxiety (McManus, Meltzer, \& Campion, 2010), compared with $15.8 \%$ in the general population (Office for National Statistics, 2017; West \& Brown, 2016). While smoking rates in many high-income countries are decreasing in the general population (West \& Brown, 2016), smoking rates are stagnating or increasing in adults with common mental disorders, and require more effective control (Centers for Disease Control and Prevention, 2012; Cook et al., 2014; Goodwin et al., 2014; Szatkowski \& McNeill, 2014). 
Several factors may account for this difference in smoking prevalence. For example, adults with mental health problems on average experience stronger addiction to nicotine (Malpass \& Higgs, 2007; Marshall, Johnson, Bergman, Gibson, \& Zvolensky, 2009; Perkins, Karelitz, Giedgowd, Conklin, \& Sayette, 2010; Royal College of Physicians \& Royal College of Psychiatrists, 2013; Weinberger, Desal, \& McKee, 2010), more severe withdrawal symptoms (Weinberger et al., 2010) and higher rates of relapse after attempting to quit compared with those without (Lukowski, Morris, Young, \& Tinkelman, 2015; O’Brien, Knight-West, Walker, Parag, \& Bullen, 2015; Piper et al., 2010; Taylor, McNeill, \& Aveyard, 2015). This may contribute to lower quit success rates (Lukowski et al., 2015; O'Brien et al., 2015) than in the general population of smokers. Despite this, smokers reporting mental health problems report a similar desire to quit smoking as those without, as well as feelings of concern for their health (Siru, Hulse, \& Tait, 2009; Weinberger, George, \& McKee, 2011). It would seem important, therefore, to use external triggers - e.g., physician advice and support - to translate this motivation into action in order to increase the likelihood of quit attempts and quit success.

A recent narrative review examined the efficacy of smoking-cessation treatments in smokers with depression over the previous two decades (Weinberger, Mazure, Morlett, \& McKee, 2013) and found that a few studies reported differences in smoking-cessation outcomes by depressive status. Furthermore, randomised controlled trials have shown that several smoking-cessation treatments can be effective at encouraging successful quit attempts in adults with mental health problems, including smoking-cessation counselling (Rogers et al., 2015), e-cigarettes (O'Brien et al., 2015), motivational interviewing interventions (Ferron et al., 2016; Steinberg, Williams, Stahl, Budsock, \& Cooperman, 2016) and nicotine replacement therapy (NRT) use (Evins, Cather, \& Laffer, 2015; Gierisch, Bastian, Calhoun, McDuffie, \& Williams, 2012; Roberts, Evins, McNeill, \& Robson, 2016). Other studies have suggested that smoking-cessation treatments need to be tailored to the specific needs of smokers reporting mental health problems (McNally \& Ratschen, 2010). For example, the Smoking Cessation Intervention for Severe Mental Ill Health Trial (SCIMITAR; Gilbody et al., 2015) reported a 13\% increase in smoking cessation a year later in smokers with severe mental health problems when the intervention was tailored to their mental illness, compared with standard treatment.

However, stop-smoking services can only be effective if they are used by the population of smokers. In the United Kingdom, National Health Service (NHS) stopsmoking services were used in less than $5 \%$ of smokers' quit attempts in 2015 (West \& Brown, 2016). It may be the acceptability or accessibility of these services that contribute to the reduction in successful quit attempts in smokers reporting mental health problems, when compared to the general population of smokers.
Brief interventions, given by General Practitioners (GPs), can also be effective in promoting smoking cessation (Stead \& Lancaster, 2012) and may be more accessible to a greater number of smokers. For instance, Very Brief Advice (VBA) on smoking has been found to be effective in triggering quit attempts in smokers while requiring a minimal time investment. In England, VBA typically involves 5 minutes or less in which the GP asks the patient whether they use tobacco, advises them to quit smoking and offers NRTs and/or referral to other quit aids if the patient is willing to quit (West, McNeill, \& Raw, 2000).VBA interventions have been related to a $40-60 \%$ increase in smoking-cessation attempts (Aveyard, Begh, Parsons, \& West, 2012), presumably because they act as a 'trigger' event for quitting, coupled with a definitive offer of support.

A few studies have explored rates of advice regarding service use from health professionals, such as GPs. Of those that have, the results are mixed and report higher (Szatkowski \& McNeill, 2013), lower (Prochaska et al., 2011) or comparable (Mitchell, Vancampfort, De Hert, \& Stubbs, 2015) rates of encouragement and support to access stop-smoking aids in smokers reporting mental health problems, compared with smokers without. Without effective encouragement and service uptake, tobacco use cannot be controlled within this population, and smoking prevalence will likely remain high.

\section{Aims}

While there is some evidence for differences in stopsmoking advice (Prochaska et al., 2011), this information is limited and no clear information is available in relation to the use of stop-smoking support. This study, therefore, is aimed to examine whether GP advice and/or offer of support, or stop-smoking service use differed between smokers reporting or not reporting depression/anxiety.

\section{Methods}

\section{Study Design}

Data were collected using cross-sectional household surveys of representative samples of the population of adults in England, conducted monthly between April and September 2012. The surveys are part of the ongoing Smoking Toolkit Study, which is designed to provide tracking information about smoking, alcohol consumption and related behaviours in England. Each month, a new sample of approximately 1,800 adults, aged $\geq 16$ years, complete a face-to-face computer-assisted survey. Full details are provided in a previous paper (Fidler et al., 2011). Ethical approval was granted by the University College London ethics committee.

\section{Participants}

A total of 10,732 adults were surveyed. The analytic sample was limited to those aged 40 years and older $(n=6,471)$ as most of the deterioration in health-related 
quality of life due to smoking would not be expected to occur until after that age. Of these, 6,411 completed the question on depression/anxiety, of which 1,162 were current cigarette smokers or recent (within the past year) exsmokers and were included in the analysis. The sample was limited to current smokers and recent $(<1$ year) exsmokers because only this group provided data on smoking and quit attempts.

\section{Measures}

Socio-demographic characteristics. Data were collected on age, gender and occupationally based classification of socio-economic status called 'social grade' (Market Research Society, 2006): $\mathrm{ABC1}=$ higher and intermediate professional/managerial and supervisory, clerical, junior managerial/administrative/professional or $\mathrm{C} 2 \mathrm{DE}=$ skilled, semi-skilled, unskilled manual and lowest grade workers or unemployed.

Smoking characteristics. Cigarette smoking status was assessed with the question: Which of the following best applies to you? (1) I smoke cigarettes (including handrolled) every day, (2) I smoke cigarettes (including handrolled), but not every day, (3) I do not smoke cigarettes at all, but I do smoke tobacco of some kind (e.g., pipe or cigar), (4) I have stopped smoking completely in the last year, (5) I stopped smoking completely more than a year ago, (6) I have never been a smoker (i.e. smoked for a year or more) or (7) Don't know. Those who responded either (1) or (2) were classed as current cigarette smokers. Those who responded (5) were classed as long-term ex-smokers and those who responded (6) were classed as never-smokers. The analytic sample comprised those who responded (1), (2), (4) to this question; the remainder were excluded as they were either not cigarette smokers (3), (6) or were not asked about the factors under consideration here (5), (7).

The number of quit attempts and cigarettes smoked per day were based on self-report. Participants were asked to state their motivation to quit smoking on the Motivation to Stop Scale (MTSS) (Kotz, Brown, \& West, 2013) from 1 (low) to 7 (high). Nicotine dependence was measured using the heaviness of smoking index (HSI) (Heatherton, Kozlowski, \& Frecker, 1989) ranging in score from 0 (low) to 6 (high).

Mental health. Anxiety/depression was assessed using an item from the EuroQol five dimensions questionnaire (EQ-5D) (Brooks, 1996). This is an established measure of health status covering five domains, including mental health. The mental health item asks respondents to choose one of the following options: (1) I am not anxious or depressed, (2) I am moderately anxious or depressed or (3) I am extremely anxious or depressed. For the purpose of analysis, scores were dichotomised into 'anxiety/depression present' (response 2 or 3 ) or 'not present' (response 1).
GP advice and use of support. GP advice was measured via the question, 'Have you spoken to your GP in the last 12 months?' to which participants could respond: (1) yes, he/she suggested that I go to a specialist stop smoking advisor or group, (2) Yes, he/she suggested that I see a nurse in the practice, (3) Yes he/she offered me a prescription for Champix, Zyban, a nicotine patch, nicotine gum or another nicotine product, (4) Yes, he/she advised me to stop but did not offer anything, (5) Yes, he/she asked me about my smoking but did not advise me to stop smoking, (6) Yes, I have seen my GP in the last year but he/she has not spoken to me about smoking, (7) No, I have not seen my GP in the last year or (8) 'don't know/can't remember'. Where participants selected more than one option, both were coded assuming that they were not mutually exclusive (response options 1-3).

Use of stop-smoking aids was assessed using three questions, which asked what methods they had used to quit on their most recent, second most recent and third most recent quit attempts. Participants were given a list of stop-smoking methods that included prescription medications (NRT, Zyban, Champix), NHS support (group or one-to-one), NHS distal support (NHS helpline or website), over the counter NRT, hypnotherapy, e-cigarettes or given the option to choose 'other' or 'nothing' (willpower or nothing). Smokers were scored as using a particular stop-smoking aid if they identified having used it at least once within their past three quit attempts. Methods were coded once, even if identified twice by the same participant.

\section{Analysis}

Data were analysed using SPSS Version 20.0, and unadjusted analysis was weighted using a rim weighting technique to match the English population profile on various socio-demographic characteristics (Fidler \& West, 2010). Differences in socio-demographic and smoking characteristics by depression/anxiety status were determined with chi-squared tests and one-way ANOVAs for categorical and continuous variables, respectively.

Linear and logistic regressions were used for the primary analysis to calculate the association between depression/anxiety status and GP advice and use of stopsmoking aids, adjusting for age, sex and social grade.

\section{Results}

The analytic sample was equally balanced in terms of gender, and the majority were in social group C2DE (Table 1). The mean age of participants was 55 years ( $\mathrm{SD}=11.1)$, with an age range of $40-92$ years. Depression/anxiety was reported by $19.0 \%$ of participants $(95 \%$ C.I. $=16.9-21.4 ; N=221$ ), with $3.8 \%$ (95\% C.I. $=2.9-$ $5.2 ; N=45)$ reporting 'extreme' anxiety/depression. Participants reporting depression/anxiety were more likely to be in a lower social group but no other statistically significant differences were found (Table 1). 
Table 1

Demographic characteristics, by mental health status (weighted)

\begin{tabular}{|c|c|c|c|c|}
\hline \multirow[b]{2}{*}{ Demographic Variables } & \multicolumn{3}{|c|}{$\%(N)$} & \multirow[b]{2}{*}{$p$-value } \\
\hline & $\begin{array}{l}\text { Overall } \\
(N=1,162)\end{array}$ & $\begin{array}{l}\text { Depression/Anxiety } \\
\text { Present }(N=221)\end{array}$ & $\begin{array}{l}\text { No Depression/ } \\
\text { Anxiety }(N=941)\end{array}$ & \\
\hline \multicolumn{5}{|l|}{ Age } \\
\hline 40-44 & $21.3(248)$ & $20.8(46)$ & $21.5(202)$ & \multirow[t]{4}{*}{0.70} \\
\hline $45-54$ & $34.2(397)$ & $31.7(70)$ & $34.8(327)$ & \\
\hline $55-64$ & $23.9(278)$ & $26.7(59)$ & $23.3(219)$ & \\
\hline $65+$ & $20.6(239)$ & $20.8(46)$ & $20.5(193)$ & \\
\hline \multicolumn{5}{|l|}{ Sex } \\
\hline Male & $49.9(580)$ & $45.2(100)$ & $51.0(480)$ & \multirow[t]{2}{*}{0.07} \\
\hline Female & $50.1(582)$ & $54.8(121)$ & $49.0(461)$ & \\
\hline \multicolumn{5}{|l|}{ Social grade } \\
\hline$A B C 1$ & $40.8(475)$ & $31.7(70)$ & $43.0(404)$ & \multirow[t]{2}{*}{0.001} \\
\hline C2DE & $59.2(688)$ & $68.3(151)$ & $57.0(537)$ & \\
\hline \multicolumn{5}{|l|}{ Smoking status } \\
\hline Smoker & $92.7(1,077)$ & $91.0(201)$ & $93.1(876)$ & \multirow[t]{2}{*}{0.17} \\
\hline Recent ( $\leq 1$ year) ex-smoker & $7.3(85)$ & $9.0(20)$ & $6.9(65)$ & \\
\hline
\end{tabular}

\section{Table 2}

Motivation to quit, quit attempts and nicotine dependence, by mental health status

\begin{tabular}{|c|c|c|c|c|c|}
\hline Smoking Variables & $\begin{array}{l}\text { Overall } \\
(N=1,286)\end{array}$ & $\begin{array}{l}\text { Depression/Anxiety } \\
\text { Present }(N=301)\end{array}$ & $\begin{array}{l}\text { No Depression/ } \\
\text { Anxiety }(N=985)\end{array}$ & OR $(95 \% \mathrm{Cl})^{3}$ & $p$-value \\
\hline Mean (SD) motivation to quit (1-7 scale) ${ }^{1}$ & $3.21(2.05)$ & $3.36(2.03)$ & $3.17(2.06)$ & $1.08(1.00-1.16)$ & 0.04 \\
\hline Mean (SD) number of quit attempts in past year & $1.56(0.93)$ & $1.61(0.96)$ & $1.54(0.92)$ & $1.46(0.85-1.40)$ & 0.48 \\
\hline Mean (SD) cigarettes smoked per day & $6.83(24.54)$ & $7.76(26.36)$ & $6.54(23.95)$ & $1.00(0.99-1.01)$ & 0.78 \\
\hline Mean (SD) Heaviness of Smoking Index scores ${ }^{2}$ & $2.03(1.52)$ & 2.39 (1.59) & $1.91(1.48)$ & $1.22(1.11-1.34)$ & $<0.001$ \\
\hline
\end{tabular}

197 cases missing.

${ }^{2} 91$ cases missing

${ }^{3}$ Adjusted for age, sex, social grade.

Depression/anxiety not present $=$ reference group

\section{Smoking Characteristics}

The majority of participants $(92.7 \%$, 95\% C.I. $=91.0-$ 94.1) were current smokers. Overall, participants had low nicotine dependence and moderate motivation to quit (Table 2). In adjusted analysis, participants reporting depression/anxiety had greater nicotine dependence, as measured by HSI, and higher motivation to quit than participants without. No difference was found in relation to cigarette consumption or the number of quit attempts made in the past year (Table 2).

\section{GP Advice and Use of Support}

Over two thirds of participants had seen their GP in the past year $(70 \%, 95 \%$ C.I. $=67.6-72.6 ; N=902)$. Of these, over a quarter were not asked about their smoking habits, and around 20\% were given advice to quit smok- ing but not offered any support (Table 3). In adjusted analysis, participants reporting depression/anxiety were more likely to have seen their GP in the past year than those without $(83.4 \%$ vs. $66.1 \%, 95 \%$ C.I. $=1.8-3.6, p<$ $.001)$. Of those who did visit their GP, participants reporting depression/anxiety were more likely to have been offered support, in particular, advice to try a stop-smoking advisor or group (Table 3). No other differences were significant.

Of participants, $30.3 \%(N=390$, 95\% C.I. $=30.9-$ 36.3) had attempted to quit at least once within the past year; of these $28.0 \%(N=116,95 \%$ C.I. $=23.9-32.5)$ used 'nothing'/'willpower' in all of their quit attempts. In adjusted analysis, no significant differences were identified between participants reporting or not reporting depression/anxiety in the stop-smoking aids they had used (Table 4). 
Table 3

Access to, and receipt of, GP advice in smokers, by mental health status

$\%(N)$

\begin{tabular}{|c|c|c|c|c|c|}
\hline \multirow[b]{2}{*}{ GP Advice } & & \multirow[b]{2}{*}{ OR $(95 \% \mathrm{Cl})^{5}$} & \multirow[b]{2}{*}{$p$-value } \\
\hline & $\begin{array}{l}\text { Overall } \\
(N=902)^{1}\end{array}$ & $\begin{array}{l}\text { Depression/Anxiety } \\
\text { Present }(N=251)^{2}\end{array}$ & $\begin{array}{l}\text { No Depression/ } \\
\text { Anxiety }(N=651)^{3}\end{array}$ & & \\
\hline Was not asked about smoking & $26.8(242)$ & $28.3(71)$ & $26.3(171)$ & $1.17(0.83-1.66)$ & 0.37 \\
\hline Was asked about smoking, no advice given & $8.5(77)$ & $6.4(16)$ & $9.4(61)$ & $0.59(0.32-1.08)$ & 0.09 \\
\hline Was asked about smoking, advice given, no support offered & $22.1(199)$ & $21.1(53)$ & $22.4(146)$ & $0.81(0.55-1.18)$ & 0.26 \\
\hline Was asked about smoking, advice given, support offered ${ }^{4}$ & $39.4(355)$ & $42.2(106)$ & $38.2(249)$ & $1.50(1.05-2.13)$ & 0.03 \\
\hline Advised to try a stop smoking advisor/group & $16.3(147)$ & $20.3(51)$ & $14.7(96)$ & $1.69(1.13-2.54)$ & 0.01 \\
\hline Advised to use NRTs & $15.5(140)$ & $16.3(41)$ & $15.2(99)$ & $1.12(0.73-1.73)$ & 0.60 \\
\hline Advised to talk to nurse & $11.4(103)$ & $11.2(28)$ & $11.5(75)$ & $1.38(0.84-2.25)$ & 0.20 \\
\hline
\end{tabular}

129 cases missing.

${ }^{2} 5$ cases missing.

${ }^{3} 24$ cases missing.

${ }^{4}$ Participants could report one or more types of advice given.

${ }^{5}$ Adjusted for age, sex, social grade.

Depression/anxiety not present $=$ reference group.

\section{Table 4}

Use of stop-smoking aid over the past three quit attempts, by mental health status

\begin{tabular}{|c|c|c|c|c|c|}
\hline \multirow[b]{2}{*}{ Aid } & \multicolumn{3}{|c|}{$\%(N)$} & \multirow[b]{2}{*}{ OR $(95 \% \mathrm{Cl})^{2}$} & \multirow[b]{2}{*}{$p$-value } \\
\hline & $\begin{array}{l}\text { Overall } \\
(N=390)^{1}\end{array}$ & $\begin{array}{l}\text { Depression/Anxiety } \\
\text { Present }(N=88)\end{array}$ & $\begin{array}{l}\text { No Depression/ } \\
\text { Anxiety }(N=302)\end{array}$ & & \\
\hline NHS, direct support ${ }^{3}$ & $8.5(33)$ & $12.5(11)$ & $7.3(22)$ & $1.97(0.75-5.19)$ & 0.17 \\
\hline NHS group & $2.8(11)$ & $3.4(3)$ & $2.6(8)$ & $2.17(0.43-10.88)$ & 0.35 \\
\hline NHS 1-to-1 & $5.9(23)$ & $10.2(9)$ & $4.6(14)$ & $2.38(0.78-7.28)$ & 0.13 \\
\hline Prescription medication ${ }^{3}$ & $32.1(125)$ & $34.1(30)$ & $31.5(95)$ & $0.94(0.54-1.65)$ & 0.83 \\
\hline NRT, prescription & $16.9(66)$ & $22.7(20)$ & $15.2(46)$ & $1.18(0.61-2.29)$ & 0.63 \\
\hline Zyban & $4.4(17)$ & $5.7(5)$ & $4.0(12)$ & $2.62(0.75-9.16)$ & 0.13 \\
\hline Champix & $13.8(54)$ & $11.4(10)$ & $14.6(44)$ & $0.72(0.30-1.70)$ & 0.45 \\
\hline NHS, distal support ${ }^{3}$ & $1.0(4)$ & $3.4(3)$ & $0.3(1)$ & - & - \\
\hline NHS helpline & $0.3(1)$ & $1.1(1)$ & $0.0(0)$ & - & - \\
\hline NHS website & $0.8(3)$ & $2.3(2)$ & $0.3(1)$ & - & - \\
\hline Other ${ }^{3}$ & - & - & - & - & - \\
\hline NRT, over the counter & $36.2(141)$ & $39.8(35)$ & $35.1(106)$ & $0.91(0.53-1.58)$ & 0.74 \\
\hline Hypnotherapy & $0.8(3)$ & $0.0(0)$ & $1.0(3)$ & - & - \\
\hline E-cigarettes & $0.3(1)$ & $1.1(1)$ & $0.0(0)$ & - & - \\
\hline Other/not stated & $7.9(31)$ & $9.1(8)$ & $7.6(23)$ & $0.74(0.27-2.00)$ & 0.55 \\
\hline
\end{tabular}

${ }^{1}$ Data were aggregated across three quit attempts, participants could select up to three options; 274 participants reported using aids in at least one quit attempt.

${ }^{2}$ Adjusted for age, sex, social grade.

${ }^{3}$ Bold indicates groupings of services below.

Depression/anxiety not present $=$ reference group.

\section{Discussion}

\section{Summary}

In this study, we compared GP advice and stop-smoking aid use in current cigarette smokers and recent exsmokers by depression/anxiety status. We identified that participants reporting depression/anxiety were more likely to have visited their doctors in the past year, and were more likely to have been offered support than smokers not reporting depression/anxiety. Use of stopsmoking aids among smokers and recent ex-smokers was 
low, and there were no significant differences recorded in stop-smoking aids used by depression/anxiety status - although this may be a type 2 statistical error. Participants reporting depression/anxiety were also shown to be more nicotine dependent than those without - as assessed by HSI, but not mean number of cigarettes smoked per day - and reported greater motivation to quit, but had a similar number of quit attempts over the past year.

\section{Strengths and Limitations}

This study reports novel findings regarding the communication between smokers and their GPs by self-reported mental health status, and the relationship between communication and service use, using an extensive population dataset. However, there are several limitations. First, we identified the presence of depression/anxiety using a single-item self-report measure. As such, prevalence may be inflated by adults experiencing border-line or mild depression/anxiety symptoms. This measure also asks participants to report their mental state on the day of data collection, rather than over a period of time and so may reflect situational distress rather than long-standing mental health conditions. Further analysis of these disorders by severity (for example, using the PHQ-9 (Kroenke \& Spitzer, 2002) and GAD-7 (Spitzer, Kroenke, Williams, \& Löwe, 2006)) may offer a clearer picture of the extent to which mental health affects GP advice and stop-smoking aid use.

Second, as data were collected retrospectively, there is a danger that differential forgetting may account for some of the observed associations. Finally, as previously mentioned, our sample consisted predominantly of current smokers with low motivation to quit. Therefore, the homogeneity of the results may be a result of the population rather than a true lack of differences in behaviour by mental health status. This may be particularly limiting when considered in conjunction with the cross-sectional design of this study, which can cause self-selection issues, and the modest sample size, which limits our ability to detect subtle differences. Further longitudinal research in larger samples could elucidate this issue.

\section{Comparison with Existing Literature}

This study reports novel findings regarding the communication between smokers and their GPs by mental health status, using an extensive population dataset. Our findings are in agreement with a previous work, which has shown that smokers reporting depression/anxiety display stronger addiction to nicotine (Malpass \& Higgs, 2007; Marshall et al., 2009; Perkins et al., 2010; Royal College of Physicians \& Royal College of Psychiatrists, 2013; Weinberger et al., 2010). We observed this association in relation to HSI score, which is a composite of cigarettes per day and time to first cigarette. The association was not evident on cigarettes per day alone, possibly because this may be driven by financial considerations rather than nicotine dependence alone. We also observed a similar number of quit attempts in current/recent ex-smokers with and without mental health problems, whereas previous research has reported a greater number of quit attempts amongst smokers with mental health issues ( $\mathrm{Zv}$ olensky, Farris, Leventhal, Ditre, \& Schmidt, 2015). This discrepancy may reflect our specific study population, which mainly comprised smokers with low motivation to quit, as opposed to smokers seeking help to quit. As such, our results may reflect a population for whom tobacco control measures have, so far, had little impact. Previous research has suggested higher motivation to quit in smokers reporting depression/anxiety (Siru et al., 2009; Weinberger et al., 2011). Our data support this observation but suggest that current smokers reporting depression/anxiety, despite being more motivated to quit, still show low overall motivation and do not attempt to quit at a higher rate than the general population of smokers. As such, they may require more support and encouragement from the health care system to follow through with quit plans.

Current/recent ex-smokers reporting depression/anxiety were more likely to have visited a doctor within the past year than those without, potentially in relation to their mental state and/or associated declines in overall health (De Hert et al., 2011; Hert et al., 2011; Musuuza et al., 2013; Osborn et al., 2007). The finding that there were no differences in GP's assessment of smoking status among those reporting or not reporting depression/anxiety contradicts earlier studies, which found that GPs are less likely to ask adults with mental health problems about their smoking because they believe that they are less likely to have the motivation or ability to quit (Prochaska et al., 2011; Szatkowski \& McNeill, 2013). As such, the results shown here may reflect the positive outcomes of previous research and interventions (such as the Quality and Outcomes Framework) encouraging GPs to consider smoking-cessation advice for patients with mental health. Furthermore, this may explain the higher motivation to quit within this subpopulation. Alternatively, it may reflect the higher motivation to quit shown in the participants reporting depression/anxiety causing them to encourage active advice-giving behaviour in their GPs, or the short-term life of the depression/anxiety measure used. It may also be affected by an increase in comorbidities (not assessed here) in smokers reporting depression/anxiety triggering a discussion from their doctor.

Encouragingly, when stop-smoking advice was given, participants reporting depression/anxiety were more likely to be offered support than those without, with no other differences apparent in GP advice. This result contrasts with a previous work involving other health professionals, including specialist mental health care workers, who express substantial reservations about providing stop-smoking advice (McNeill \& Shahab, 2016). This may be due to a feeling of responsibility for physical health in GPs in which may not be the primary concern of mental 
health professionals. This is important, as research suggests that the effectiveness of stop-smoking advice alone is enhanced when an active offer of support is made (Aveyard et al., 2012). Providing advice, even if very brief, has been shown to boost quit rates (Roberts, Kerr, \& Smith, 2013; Stead et al., 2013), and so these results are reassuring for the future uptake of smoking cessation in smokers with mental health issues.

However, no difference was found in actual use of support by mental health status. This may reflect the small number of participants who reported using stop-smoking aids. Alternatively, it may suggest a lack of enthusiasm for group support in those reporting depression/anxiety, or a lack of appropriate smoking-cessation material for adults feeling depressed/anxious within these groups (Gilbody et al., 2015; McNally \& Ratschen, 2010). Smokers reporting depression/anxiety may, for example, feel that their experiences are unrelated to those experienced by other smokers, or may feel daunted by the thought of expressing their problems in front of groups; although this has not been explored in the literature. Without further exploration of the factors driving the results presented here, it is unlikely that tobacco control measures will effectively reduce smoking rates in smokers reporting mental health issues.

\section{Conclusions}

This study presented evidence that smokers reporting depression/anxiety show greater motivation to quit but also experience stronger nicotine dependence than those without, and so are likely to require greater support to quit successfully. Although smokers who report anxiety or depression appear to be more likely to be offered stopsmoking support than other smokers, they are no more likely to take up the offer. Further tailored input may therefore be required to turn this offer of support into an actual use of stop-smoking aids.

\section{Financial Support}

We are grateful to Cancer Research UK and the British Heart Foundation for funding this analysis (C27061/A18679). The Smoking Toolkit Study is primarily funded by Cancer Research UK (C1417/A14135, C36048/A11654, C44576/A19501) and has previously also been funded by Pfizer, GSK and the Department of Health. JB's post is funded by a fellowship from the Society for the Study of Addiction and is also supported by CRUK (C1417/A14135). Robert West is funded by Cancer Research UK (C1417/A14135). LS is a HEFCE funded member of staff at University College London. JM is funded by an innovation grant from Cancer Research UK (C42785/A20811) and the National Centre for Smoking Cessation.

\section{Conflict of Interest}

LS has received an honorarium for a talk, an unrestricted research grant and travel expenses to attend meetings and workshops from Pfizer, a pharmaceutical company that makes smoking-cessation products, and has acted as paid reviewer for grant awarding bodies and as a paid consultant for health care companies. JB has received an unrestricted research grant from Pfizer to study population trends in smoking. RW has received travel funds and hospitality from, and undertaken research and consultancy for, pharmaceutical companies that manufacture or research products aimed at helping smokers to stop. The other authors have no conflicts of interest to declare.

\section{Contributors}

LS conceived the original idea for this study. RW obtained funding and JB managed the day-to-day running of the study. JM undertook the data analyses and wrote the initial draft with further input from LS, JB, RW and LB. JM is guarantor for this article. All authors read, reviewed and approved the final version. All researchers listed as authors are independent from the funders and all final decisions about the research were taken without constraint by the investigators. LS and JM had full access to all the data in the study and JM had final responsibility for the decision to submit for publication.

\section{Ethical Standards}

The authors assert that all procedures contributing to this work comply with the ethical standards of the relevant national and institutional committees on human experimentation and with the Helsinki Declaration of 1975, as revised in 2008.

\section{References}

Aveyard, P., Begh, R., Parsons, A., \& West, R. (2012). Brief opportunistic smoking cessation interventions: A systematic review and meta-analysis to compare advice to quit and offer of assistance. Addiction, 107, 1066-1073.

Brooks, R. (1996). EuroQol: The current state of play. Health Policy, 37, 53-72.

Callaghan, R. C., Veldhuizen, S., Jeysingh, T., Orlan, C., Graham, C., Kakouris, G. et al. (2014). Patterns of tobacco-related mortality among individuals diagnosed with schizophrenia, bipolar disorder, or depression. Journal of Psychiatric Research, 48, 102-110.

Centers for Disease Control and Prevention (2012). Smoking among U.S. adults with mental illness 70 percent higher than for adults with no mental illness. Washington, DC: U.S. Department of Health \& Human Services.

Chesney, E., Goodwin, G. M., \& Fazel, S. (2014). Risks of allcause and suicide mortality in mental disorders: A metareview. World Psychiatry, 13, 152-160.

Cook, B. L., Wayne, G. F., Kafali, E. N., Liu, Z., Shu, C., \& Flores, M. (2014). Trends in smoking among adults with mental illness and association between mental health treatment and 
smoking cessation. Journal of the American Medical Association, 311, 172-182.

De Hert, M., Cohen, D., Bobes, J., Cetkovich-Bakmas, M., Leucht, S., Ndetei, D. M. et al. (2011). Physical illness in patients with severe mental disorders. II. Barriers to care, monitoring and treatment guidelines, plus recommendations at the system and individual level. World Psychiatry, 10, 138151.

Evins, A. E., Cather, C., \& Laffer, A. (2015). Treatment of tobacco use disorders in smokers with serious mental illness: Toward clinical best practices. Harvard Review of Psychiatry, 23, 90-98.

Ferron, J. C., Devitt, T., McHugo, G. J., Jonikas, J. A., Cook, J. A., \& Brunette, M.F. (2016). Abstinence and use of community-based cessation treatment after a motivational intervention among smokers with severe mental illness. Community Mental Health Journal, 52, 446-456.

Fidler, J. A., Shahab, L., West, O., Jarvis, M. J., McEwan, A., Stapleton, J. A. et al. (2011). 'The smoking toolkit study': A national study of smoking and smoking cessation in England. BMC Public Health, 11, 479-488.

Fidler, J. A. \& West, R. (2010). Changes in smoking prevalence in 16-17-year-old versus older adults following a rise in legal age of sale: Findings from an English population study. Addiction, 105, 1984-1988.

Gierisch, J. M., Bastian, L. A., Calhoun, P. S., McDuffie, J. R., \& Williams, J. W. Jr. (2012). Smoking cessation interventions for patients with depression: A systematic review and metaanalysis. Journal of General Internal Medicine, 27, 351-360.

Gilbody, A., Peckham, E., Man, M.-S., Mitchell, N., Li, J., Becque, T. et al. (2015). Bespoke smoking cessation for people with severe mental ill health (SCIMITAR): A pilot randomised controlled trial. The Lancet Psychiatry, 2, 395-402.

Goodwin, R. D., Wall, M. M., Choo, T., Galea, S., Horowitz, J., Nomura, Y. et al. (2014). Changes in the prevalence of mood and anxiety disorders among male and female current smokers in the United States: 1990-2001. Annals of Epidemiology, 24, 493-497.

Heatherton, T. F., Kozlowski, L. T., \& Frecker, R. C. (1989). Measuring the heaviness of smoking: Using self-reported time to the first cigarette of the day and number of cigarettes smoked per day. British Journal of Addiction, 84, 791-799.

Hert, D. E., Correl, C. U., Bobes, J., Cetkovich-Bakmas, M., Cohen, D., Asai, I. et al. (2011). Physical illness in patients with severe mental disorders. I. Prevalence, impact of medications and disparities in health care. World Psychiatry, 10, $52-77$.

Kotz, D., Brown, J., \& West, R. (2013). Predictive validity of the motivation to stop scale (MTSS): A single-item measure of motivation to stop smoking. Drug and Alcohol Dependence, $128,15-19$.

Kroenke, K. \& Spitzer, R. L. (2002). The PHQ-9: A new depression diagnostic and severity measure. Psychiatric Annals, 32, 509-515.

Lukowski, A. V., Morris, C. D., Young, S. E., \& Tinkelman, D. (2015). Quitline outcomes for smokers in 6 states: Rates of successful quitting vary by mental health status. Nicotine \& Tobacco Research Advance Access, 17, 924-930.

Malpass, D. \& Higgs, S. (2007). Acute psychomotor, subjective and physiological responses to smoking in depressed outpatient smokers and matched controls. Psychopharmacology, 190, 363-372.

Market Research Society (2006). Occupation groupings: A job dictionary. London: Market Research Society.

Marshall, E. C., Johnson, K., Bergman, J., Gibson, L. E., \& Zvolensky, M. J. (2009). Anxiety sensitivity and panic reactivity to bodily sensations: Relation to quit-day (acute) nicotine withdrawal symptom severity among daily smokers making a self-guided quit attempt. Experimental and Clinical Psychopharmacology, 17, 356-364.

McManus, S., Meltzer, H., \& Campion, J. (2010). Cigarette smoking and mental health in England: Data from the adult psychiatric morbidity survey 2007.

McNally, L. \& Ratschen, E. (2010). The delivery of stop smoking support to people with mental health conditions: A survey of NHS stop smoking services. BMC Health Services Research, 10, 179-184.

McNeill, A. \& Shahab, L. (2016). A mixed-method systematic review and meta-analysis of mental health professionals' attitudes toward smoking and smoking cessation amongst people with mental illnesses. Addiction, 111(9), 1536-1553.

Mitchell, A. J., Vancampfort, D., De Hert, M., \& Stubbs, B. (2015). Do people with mental illness receive adequate smoking cessation advice? A systematic review and metaanalysis. General Hospital Psychiatry, 37, 14-23.

Musuuza, J. S., Sherman, M. E., Knudsen, K. J., Sweeney, H. A., Tyler, C. V., \& Koroukian, S. M. (2013). Analyzing excess mortality from cancer among individuals with mental illness. Cancer, 119, 2469-2476.

O'Brien, B., Knight-West, O., Walker, N., Parag, V., \& Bullen, C. (2015). E-cigarettes versus NRT for smoking reduction or cessation in people with mental illness: Secondary analysis of data from the ASCEND trial. Tobacco Induced Diseases, 13, eCollection 2015.

Office of National Statistics (2007). Adult psychiatric morbidity in England, 2007.

Osborn, D. P., Levy, G., Nazareth, I., Petersen, I., Islam, A., \& King, M. B. (2007). Relative risk of cardiovascular and cancer mortality in people with severe mental illness from the United Kingdom's general practice research database. Archives of General Psychiatry, 64, 242-249.

Perkins, K. A., Karelitz, J. L., Giedgowd, G. E., Conklin, C. A., \& Sayette, M. A. (2010). Differences in negative moodinduced smoking reinforcement due to distress tolerance, anxiety sensitivity, and depression history. Psychopharmacology, 210, 25-34.

Piper, M. E., Smith, S. S., Schlam, T. R., Fleming, M. F., Bittrich, A. A., Brown, J. L. et al. (2010). Psychiatric disorders in smokers seeking treatment for tobacco dependence: Relations with tobacco dependence and cessation. Journal of Consulting and Clinical Psychology, 78, 13-23. 
Prochaska, J. J., Reyes, R. S., Schroeder, S. A., Daniels, A. S., Doederlein, A., \& Bergeson, B. (2011). An online survey of tobacco use, intentions to quit, and cessation strategies among people living with bipolar disorder. Bipolar Disorder, 13, 466-473.

Roberts, E., Evins, A. E., McNeill, A., \& Robson, D. (2016). Efficacy and tolerability of pharmacotherapy for smoking cessation in adults with serious mental illness: A systematic review and network meta-analysis. Addiction, 111, 599-612.

Roberts, N. J., Kerr, S. M., \& Smith, S. M. (2013). Behavioral interventions associated with smoking cessation in the treatment of tobacco use. Health Services Insights, 6, 7985.

Rogers, E. S., Smelson, D. A., Gillespie, C. C., Elbel, B., Poole, S., Hagedom, H. J. et al. (2015). Telephone smokingcessation counseling for smokers in mental health clinics. American Journal of Preventive Medicine, 50, 518527.

Royal College of Physicians \& Royal College of Psychiatrists (2013). Smoking and mental health: A joint report by the Royal College of Physicians and the Royal College of Psychiatrists. London: Royal College of Physicians.

Schlam, T. R. \& Baker, T. B. (2013). Interventions for Tobacco Smoking. Annual Review of Clinical Psychology, 9, 675-702.

Siru, R., Hulse, G. K., \& Tait, R. J. (2009). Assessing motivation to quit smoking in people with mental illness: A review. Addiction, 104, 719-733.

Spitzer, R. L., Kroenke, K., Williams, J. B., \& Löwe, B. (2006). A brief measure for assessing generalized anxiety disorder: The GAD-7. Journal of the American Medical Association, 166, 1092-1097.

Stead, L. F., Buitrago, D., Peciado, N., Sanchez, G., HartmannBoyce, J., \& Lancaster, T. (2013). Does advice from doctors encourage people who smoke to quit. Cochrane Reviews, 31(5), CD000165.

Stead, L. F. \& Lancaster, T. (2012). Combined pharmacotherapy and behavioural interventions for smoking cessation (Review). Cochrane Database of Systematic Reviews, 10, CD008286.

Steinberg, M. L., Williams, J. M., Stahl, N. F.,Budsock, P.D., \& Cooperman, N. A. (2016). An adaptation of motivational interviewing increases quit attempts in smokers with serious mental illness. Nicotine and Tobacco Research, 18, 243250.

Szatkowski, L. \& McNeill, A. (2013). The delivery of smoking cessation interventions to primary care patients with mental health problems. Addiction, 108, 1487-1494.

Szatkowski, L. \& McNeill, A. (2014). Diverging trends in smoking behaviors according to mental health status. Nicotine \& Tobacco Research, 17, 356-360.

Tam, J., Warner, K. E., \& Meza, R. (2016). Smoking and the reduced life expectancy of individuals with serious mental illness. Am J Prev Med, 51(6), 958-966.

Taylor, G., McNeill, A., \& Aveyard, P. (2015). Does deterioration in mental health after smoking cessation predict relapse to smoking? BMC Public Health, 15, 1150-1157.

Weinberger, A. H., Desal, R. A., \& McKee, S. A. (2010). Nicotine withdrawal in US smokers with current mood, anxiety, alcohol use, and substance use disorders. Drug and Alcohol Dependence, 108, 7-12.

Weinberger, A. H., George, T. P., \& McKee, S. A. (2011). Differences in smoking expectancies in smokers with and without a history of major depression. Addictive Behaviors, 36, 434437.

Weinberger, A. H., Mazure, C. M., Morlett, A., \& McKee, S. A. (2013). Two decades of smoking cessation treatment research on smokers with depression: 1990-2010. Nicotine \& Tobacco Research, 15, 1014-1031.

West, R. \& Brown, J. (2016). Monthly tracking of key performance indicators: Latest trends on smoking in England. The smoking toolkit study.

West, R., McNeill, A., \& Raw, M. (2000). Smoking cessation guidelines for health professionals: An update. Thorax, 55, 987-999.

Wu, Q., Szatkowski, L., Britton, J., \& Parrott, S. (2013). Economic cost of smoking in people with mental disorders in the UK. Tobacco Control, 24, 462-468.

Zvolensky, M. J., Farris, S. G., Leventhal, A. M., Ditre, J. W., \& Schmidt, N. B. (2015). Emotional disorders and smoking: Relations to quit attempts and cessation strategies among treatment-seeking smokers. Addictive Behaviors, 40, 126131. 